acetal $\mathrm{C}^{4} \mathrm{H}^{4}\left(\mathrm{C}^{2} \mathrm{H}^{3}\right)^{2} \mathrm{O}^{4}$, eine Verbindung, die bekanntlich Wurtz zuerst auf anderem Wege darstellte und die völlig identisch ist mit der auf obige Weise gewonnenen. Der Kochpunct, den Kekulé und Limpricht in ihren Lehrbüchern dafür angeben, ist durch einen Druckfehler in Liebig's Annalen auf 550 gesetzt, während Wurtz selbst $65^{\circ}$ angiebt. Der Gehalt des rohen Holzgeistes an Dimethylacetal ist schwankend, einige Proben enthielten im Liter 20, andere nur $10 \mathrm{Grm}$. Darnach ist der rohe Holzgeist ein Gemenge von Methylalkohol, Aceton, essigsaurem Holzäther und Dimethylacetal, das bisher angenommene Lignon oder der Xylit aber existirt nicht. (Journ. fiir prakt. Chemie. Bd. 94. 8.)

B.

\title{
Neue Synthesen der Ameisensäure.
}

Richard L. Maly erzeugte Ameisensäure durch Einwirkung des eben freiwerdenden Wasserstoffs auf Kohlensäure, die in alkalischer Lösung vom Ammoniak auf das Natron übergeht.

I. In eine concentrirte Lösung von kohlensaurem Ammoniak wurde allmälig verdünntes (flüssiges) N a tri u ma malg am eingetragen; nachdem alles erzeugte Ammoniumamalgam sich unter Wasserstoffentwickelung wieder zersetzt hatte, wurde die Flüssigkeit vom Quecksilber abgegossen, mit verdünnter Schwefelsäure übersättigt, destillirt, das saure Destillat mit $\mathrm{NaO}, \mathrm{CO}^{2}$ neutralisirt und abgedampft, worauf die erhaltene Salzmasse in wenig Wasser gelöst salpetersaures Silberoxyd und Sublimat beim Kochen reducirte, mit $\mathrm{HO}, \mathrm{SO}^{3}$ Kohlenoxydgas entwickelte u. s. w. Das Destillat einer neuen Darstellung wurde mit $\mathrm{PbO}, \mathrm{CO}^{2}$ heiss neutralisirt; das Filtrat zeigte beim Abdampfen eine schöne Krystallisation von feinen, seidenglänzenden Nadeln, die in allen Eigenschaften mit dem ameisensauren Bleioxyd übereinstimmten.

0,4465 Grm. dieses Bleisalzes gaben 0,454 Grm. $\mathrm{PbO}, \mathrm{SO}^{3}=0,31015 \mathrm{Grm}$. Blei $=69,5$ Proc. Blei. 'Das $\mathrm{PbO}, \mathrm{C}^{2} \mathrm{HO}^{3}$ verlangt 69,7 Proc $\mathrm{Pb}$.

Die Bildung der Ameisensäure aus $\mathrm{H}$ und $\mathrm{C}_{2}^{2} \mathrm{O}^{4}$ lässt sich durch die Gleichung ausdrücken:

$2 \mathrm{H}^{4} \mathrm{NO}, \mathrm{C}^{2} \mathrm{O}^{4}+2 \mathrm{Na}=2 \mathrm{H}^{3} \mathrm{~N}+2 \mathrm{NaO}+2 \mathrm{H}$

$+\mathrm{C}^{2} \mathrm{O}^{4}=2 \mathrm{H}^{3} \mathrm{~N}+\mathrm{NaO}, \mathrm{HO}+\mathrm{NaO}, \mathrm{C}^{2} \mathrm{HO}^{3}$.

II. Trägt man in eine heisse Kalilauge ein Gemenge von Zinkpulver und kohlensaurem Zinkoxyd, so addirt sich der eben freiwerdende Wasserstoff ebenfalls zu dem 
in Bildung begriffenen kohlensauren $\mathrm{Kali}$ und liefert (obgleich nur sehr wenig) ameisensaures Kali.

Man sieht hieraus genau die Bedingungen zur Synthese der Ameisensäure, nämlich:

1. nascirender Wasserstoff, 2. Kohlensäure im Momente der Uebertragung, 3. Gegenwart einer kräftigen Basis. In diesem Sinne interpretirt sich auch der erste Versuch dieser Art von Kolbe und Schmitt, (Ann. d. Chen. u. Pharm. Bd. 119. p. 251), welche Kalium unter einer mit lauwarmem Wasser abgesperrten und mit Kohlensäure gefüllten Glasglocke ausgebreitet liessen.

(Sitzungsber. d. k. Akad. d. Wissensch. Math.-nat. Classe. LI. Bd. III. H. Jahrg. 1865, März. II. Abth. S. 244-246.)

H. Ludwig.

\section{Veber neue lösliche Permente.}

Wenn in einer Rohrzuckerlösung Schimmelbildung eintritt, so findet bekanntlich eine Intervertirung (Modificirung) des Zuckers statt, eben so wenn Hefe oder nach Mits cherlich das von Hefe abfiltrirte Wasser mit Zuckerlösung vermischt wird. Die Substanz, welche im Fall der Schimmelbildung als Ferment auftritt, hat A. Bécha mp (Compt. rend. 59.) zu isoliren versucht und sie mit dem Namen Zymase belegt. Dieselbe ähnelt in ihrer Wirkung derjenigen der Diastase auf Stärkemehl, aber sie macht keinen Stärkekleister flüssig und verwandelt ihn weder in Dextrin, noch in Zucker. Bei $60-70^{\circ}$ wird ihre Fermentationskraft völlig zerstört.

Dass die nicht grünen, aber sonst gefärbten Pflanzenbestandtheile die Rolle eines Ferments nach einer älteren Bemerkung Dumas' spielen können, führte Bécham auf die Vergleichung der Schimmelbildungen mit dergleichen Pflanzenbestandtheilen und veranlasste ihn zu Versuchen, die Zymase auch in den letzteren aufzusuchen, um zu sehen, ob sie mit der in den Schimmelbildungen vorhandenen identisch oder nur analog sei. Das Verfahren für die Isolirung der Zymase war dasselbe, welches Payen und Persoz für die Gewinnung der Diastase empfohlen haben: Ausziehen mit Wasser, Fällen durch Alkohol, Lösung des mit Alkohol ausgewaschenen Niederschlags in Wasser und Wiederfällung mit Alkohol. Um nachzuweisen, dass ein Pflanzenbestandtheil, z. B. Blumenblätter, Zymase enthalte, zerquetscht man ihn, presst den Saft aus und setzt von die- 